TI 2012-079/3

Tinbergen Institute Discussion Paper
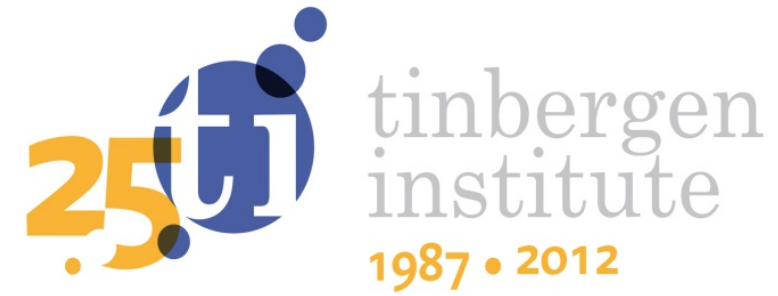

\title{
Altruism to Strangers for our Own Sake: Domestic Effects from Immigration
}

\author{
Annie Tubadjir \\ Peter Nijkamp²
}

I Instituts für Arbeidsmarkt- und Berufsforschung (IAB), and University of Regensburg;

2 Faculty of Economics and Business Administration, VU University Amsterdam, and Tinbergen Institute. 
Tinbergen Institute is the graduate school and research institute in economics of Erasmus University Rotterdam, the University of Amsterdam and VU University Amsterdam.

More TI discussion papers can be downloaded at http://www.tinbergen.nl

Tinbergen Institute has two locations:

Tinbergen Institute Amsterdam

Gustav Mahlerplein 117

1082 MS Amsterdam

The Netherlands

Tel.: +31(0)205251600

Tinbergen Institute Rotterdam

Burg. Oudlaan 50

3062 PA Rotterdam

The Netherlands

Tel.: +31(0)10 4088900

Fax: $+31(0) 104089031$

Duisenberg school of finance is a collaboration of the Dutch financial sector and universities, with the ambition to support innovative research and offer top quality academic education in core areas of finance.

DSF research papers can be downloaded at: http://www.dsf.nl/

Duisenberg school of finance

Gustav Mahlerplein 117

1082 MS Amsterdam

The Netherlands

Tel.: +31(0)20 5258579 


\title{
ALTRUISM TO STRANGERS FOR OUR OWN SAKE: DOMESTIC EFFECTS FROM IMMIGRATION
}

\author{
A Comparative Analysis for EU15
}

\author{
Annie TUBADJI \\ Instituts für Arbeitsmarkt- und \\ Berufsforschung (IAB) \\ and University of Regensburg \\ Regensburg, Germany \\ annie.tubadji@iab.de
}

\author{
Peter NIJKAMP \\ Dept. of Spatial Economics \\ VU University, Tinbergen Institute \\ Amsterdam, The Netherlands \\ pnijkamp@feweb.vu.nl
}

\begin{abstract}
This paper seeks to identify relationships between human capital and cultural capital, in the context of local labour market productivity. The key constituents of human capital, identified in the literature, are jointly examined in a close-to-reality-model. The main advantage of our model of productivity is that, in addition to accounting for the filigree composition of human capital, it also takes into consideration the cultural capital present in a locality. In this manner, we are able to examine the interaction between the quality of the incoming human capital and the cultural encounter context (generating the cultural "milieu" effect) of the modern diverse city. To this end, we operationalize one model with data on the 'melting pot' of EU15, at NUTS2 level. The sources of our data are the Eurostat Regional Database and the World Value Survey, which have served to construct both a cross-section for the year 2001. These datasets allows us: (1) to examine the different groups of migrating and local human capital, their interaction and joint impact on local productivity, and (2) to cross-check for the causality direction behind our model. Our findings suggest that benefits from immigrants differ, not only due to their human capital, but also due to their culturally biased different bargaining power on the labour market.
\end{abstract}

Keywords: human capital, cultural capital, diversity, productivity, growth, Weber

JEL-classification: Z10, O31, O43, R11 


\section{Introduction}

While it is commonly accepted that local development is a product of human activity in a locality, the human mobility effects on productivity are still at large a "black box" and therefor often considered a Pandora’s box.

Fears and preoccupation with securing the local welfare have focused the attention onesidedly on researching the benefits and/or threats carried by the inflowing foreign human capital (we use a broad definition of human capital here as any high or low skilled individual with creative potential). Research has delved into the different characteristics of immigrants (their educational level, social networking within the immigrants groups, the local diversity that they create etc.) hoping to explain and predict their potential to affect local productivity. Contradictive evidence for the effects of immigrants has been gathered following this onesided analysis which has only increased the alertness towards the Pandora box of allowing further inflows of foreigners. If we want to be realistic however, we should recognize that the immigration impact is not a one way development determined solely by the quality and activity of the immigrants themselves.

Migration is indeed one of the oldest and most vastly researched phenomena, but to sum it up in an adequate economic model for productivity we should recognize that migration reallocates human capital in the context of the locality. Thus migration leads to recomposition of the local human capital. But this does not have immediate effect on productivity. First, two groups - local and foreign - encounter on a territory, where the local group has higher bargaining power than the foreigners. The locals as carriers of the local culture have better knowledge and more appropriate social skills vis a vis the local formal and informal institutions. The way these two groups will perform in the labour market competition and in the social field is not at all standard mechanics, but highly socially and culturally sensitive process. Sociology has delved into the details of this process with great care and attention, but economics seems to see it still over-simplistically schematic. Economics needs to recognize that the effects of migration cannot be detected solely through investigating the quality of the inflow of human capital. We need simultaneously to understand and account for the dynamics of the encounter between the incoming and local human capital. The characteristics of the incoming human capital undeniably matter. But it is the dynamics of cultural encounters between locals and foreigners which has the decisive power on the sign and magnitude of the immigrant effect. This dynamics determines how much the immigrant potential (whatever it is as quality) can achieve realization locally and for what types of activities this potential will be utilized.

Our inquiry aims at undertaking the task of considering simultaneously in regional economics context both the action and interaction effects from immigrants in search for a more plausible 
and close to reality explanation of the immigrant effects inconsistencies throughout the culturally diverse Europe.

The structure of the paper continues as follows: Section 2 deals with the development of of different types of human capital and its relation to as a notion and provides the working definitions for this paper. Section 3 explains the cultural interaction mechanism which can be seen as the missing element from the state-of-the art models linking immigration and economic development. Here we refer to the popular cultural attraction effects which are usually present in the standard models. Section 4 describes the main mechanisms of cultural impact on local economies addressed in this study. Section 5 presents our database and estimation strategy and discusses the results. Section 5 concludes.

\section{Types of Human Capital in a Locality}

The issues of human capital were debated by economics for a really long while. Adam Smith (1776) defined the acquired through education, study and apprenticeship skills, the dexterity and talents of the labour force as determinants for the useful input a worker can contribute as inhabitant or member of the society. It took time for economics to assimilate this definition in its full depth. For long it was interpreted as labour being a homogenous capital of easily substitutable components which represents a factor of production. In such a homogenous labour force the mechanical division of labour through specialization on particular tasks would suggest direct positive effect for productivity. Therefore, neoclassical economics developed the understanding for investment in formation of the necessary specialization of labour coining the term human capital (Pigou 1928; Mincer 1958; Becker 1964). However, with time economists realized that there are different segments of this human capital which have better or worse dexterity and talent for different tasks. This fact had to be recognized by economic science (and was recognized mostly by entrepreneurship literature such as Shapero, Sokol 1982; Krueger, Brazeal 1994; Krueger et. al. 2000) since it determines the significantly different effect that one and the same specialization can have depending on which workers are specialized for the required tasks (Florida 2002a,b).

Gradually, the literature managed to identify four main sub-groups of labour according to the skills and potentials (i.e. the human capital) needed to implement the specific type of labour tasks. Namely, there are the subgroups of: 1) skilled labour (highly educated), 2) non-skilled labour (with low level of education), 3) creative labour (workers with potential to make crucial decisions about the task implementation and able to undertake entrepreneurship) (see Florida 2002a,b; Tüzin, Nijkamp 2011) and 4) routine labour (workers used for mechanical implementation of routine sets of instructions) (see Autor, Dorn 2009; Blinder 2007; Blinder, Krueger 2009). The creatives and high-skilled workers are the fuel for the locomotive of 
economic development in a locality (mostly through R\&D and entrepreneurship), while the routine and non-skilled labour correlate mostly with the scale of production. The creatives and high skilled are also the ones whose bigger share in a locality (when still efficient for production needs) determines higher local productivity among localities (Florida 2002a,b, 2005). Thus was formed the operating modern latently present definition of human capital as groups of useful for production and growth skills and potentials, which can have high or low composition in the labour force of a locality.

These groups of different human skills and potentials however do not exist as strictly separate entities of human capital but are present in different combinations within different individuals and the aggregate sum of the combinations determines the human capital level in the locality.

It is known that different types of human capital can have different labour power to the employees (Marx 1867). It is also known that knowledge is the component through which creative labourers (especially researchers) contribute to the production process (Romer 1986, 1990a,b). Therefore we assume that different types of human capital could guarantee different labour power to the employees because they could gain different access to the existing knowledge. Workers have different potential to impact productivity and growth which respectively gives them different bargaining power on the labour market. And the neoclassical perfect labour market equilibrium would exist if: 1) the labour market was closed and only certain human capital was available and all the available human capital had all other starting conditions (such as origin or accent, or attitudes) equal; 2) employers could be objectively informed of the full human capital potential of a worker - on both his skills and his creativity. People however tend to be different, tend to be mobile and tend to make culturally biased judgments about the potentials of others (Bourdieu 1977). The existing jobs needing to employ particular form of human capital have first to be matched with labourers having such human capital. The matching though passes through the employer's choice, and human choice is subject to cultural bias. This is especially essential for the evaluation of the creative human capital which is not always certifiable through credentials and official documents.

To sum up, we should take into account that before becoming an entry into the local production function, the productivity determining mixture of human capital attracted in a locality pours first into the local "melting pot" of the culturally diverse city (Jacobs 1961). Thus the diversity created by the current and lagged mobility of the human capital is only the stage for the encounter between strangers and incumbent population embedded in the local cultural beliefs and values (Polanyi 1968). Therefore, the diversity is only the context of the cultural interaction, while this interaction during the cultural encounter is what determines if we will observe a Babylon effect or a creative enrichment effect in the diverse society. 


\section{Cultural Interaction between the Different Human Capital Groups in a Locality}

Part of the skilled and non-skilled labour is creative, while the other part is not. However the distribution of the creative and non-creative parts of skilled and non-skilled labour passes through the labour market competition for creative vs routine jobs. This competition happens on the basis of both objective and subjective criteria (Bowles, Gintis 1975). The objective criteria themselves are not equal since different groups of immigrants (with EU and non-EU origin for instance, see Nijkamp et.al. (2011)) face different legal barriers for entry on the labour market and therefore have different bargaining power on the job market. Moreover, there are subjective criteria ruled by the cultural capital, as explained by Bourdieu (1986) where cultural background helps or hinders the promotion of an individual in a society in addition to his actual level of skills. Thus individuals with the right cultural capital will actualize their skills more successfully than workers with less powerful cultural capital. As is natural to be expected, the local cultural capital has a stronger institutional power than the power of the foreign group in the locality. In this culture-based part of the labour market competition lies the key determinant for the impact that immigrants will have in the new locality. Creativity coming from locals will be easier to institutionalize as a new set of rules, compared to new instructions coming from outsiders. Moreover, foreign creative competitors with lower skills will be countered with higher skills and the social reproduction power of cultural capital (Bourdieu 1973; Bourdieu, Passeron 1977) promoting the locals over the newcomers. On one side, this cultural mechanism will support the local workers and ensure their employment and individual welfare. However, it leads to lop-siding the natural distribution of creative workers to creative occupations. This lop-siding ends up in reallocating highly skilled but non-creative local work force to creative occupations, while creative immigrants (with high or low skills) can be distributed by the cultural mechanism to routine occupations. This happens with low levels of awareness, because the cultural bias serves as justification of the lop-sided choice as commonly rational for the local population. Thus, the potential positive impact of the creative part of the immigrants on aggregate level for local productivity can be abolished due to locals' strive and majority common agreement for guaranteeing their individual welfare first. In the short run, this could result in positive welfare outcome for the locals. But in the long run, the overall productivity is lower than it could be, while the number of consumers is higher than before. Thus, when lop-siding of human capital allocation has occurred, in the long run both locals and foreigners in the locality end up worse off.

This is a cultural capital based mechanism of diversity quite different from the standard approach to diversity as a lagged migration effect of human capital. To know if migration will have good or bad consequences, we are interested to predict the sign and magnitude of the effect of diversity in a locality. When we account only for the number of different ethnical 
groups of people present in a locality (Ottaviano, Peri 2004, 2005, 2006; Ottaviano, Prarolo 2009), no matter how mathematically precisely we measure the effect of this number, all that we can capture through it is the magnitude of the effect from cultural diversity. Only when we consider the cultural capital leverage which drives the culture-based competition and interaction between local and incoming human capital, then we can finally capture the full effect from diversity. This can be seen as a neo-Weberian mechanism of cultural impact on socio-economic development. We use the term 'neo-Weberian' here in the sense that it explains a lop-siding of the optimal employment choice due to cultural bias. In other words, our approach captures the dependence of rational choice on culture. And therefore we consider necessary to acknowledge that it is Max Weber who dedicated some of his life-time research on the differences between rationality according to the different cultural background (approximated by religion). Yet, more precisely, our 'neo-Weberian' mechanism expresses the influence of cultural capital on the competition and interaction of the different forms of human capital. Independent of the more objective skill-level criteria, cultural capital has the decisive role for the allocation of the foreign vs local human capital to the actual tasks and jobs on the labour market. This allocation process is executed by rational choice of the employer and rationality differs according to cultural background. Thus we end up with the clear cut mechanism: creative human capital allocation depends on the rational choice of the employer, employer's rationality depends on his culture, therefore the allocation of creative capital depends on the local culture to which the employer belongs. Moreover, creative human capital with cultural proximity will have higher chances of successful allocation to creative tasks because her/his cultural background empowers her/him with better social skills and local institution knowledge in the bargaining process with the employer.

\section{A Two Gear Mechanism of Cultural Attraction and Cultural Interaction for Groups with Different Human Capital in a Locality}

In summary of the reasoning presented in the previous three sections, to capture properly the process of the cultural effect through immigration we can translate the local cultural capital influence into a structure of a two-gears-mechanism of impact. The two gears of this model of cultural impact are as follows. First, local cultural capital attraction for immigrants should be understood as a first gear of impact that captures the effect of cultural milieu as a factor for attracting foreign human capital in a locality. Second, the interaction of local cultural capital and the overall accumulated human capital in the locality act as a second gear of cultural impact onthe local productivity, accounting for the effect of diversity on competition and job allocation. Aiming to examine this dual mechanism of impact, the current paper takes up with tracing evidence for the cultural impact in reverse order. Two main hypotheses are to be 
tested in order to consider we have identified traces which successfully reconstruct the two gear mechanism:

H01: The different groups of immigrants generate different impact on local productivity.

H02: The concentration of different groups of human capital (creative, skilled and foreign) is strongly dependent on the local cultural capital.

It is important to follow this reverse order of testing, in order to: 1) identify if indeed different immigrants have different impact and 2), if so, to identify are there cultural reasons explaining the distribution of different groups of human capital (including the inflow of foreign human capital in a locality). Thus, H01 tests for evidence on the gear of interaction and in case this hypothesis is not failed, we proceed to H02, which explains the primary reason or the different effects from immigrants - the gear of cultural attraction.

To test the above hypotheses we need to take several measurement issues into consideration. The immigrants as a variable are also expected to behave according to normal Harris-Todaro expectations, i.e. depending on wages and unemployment. However, what has a decisive role of the productivity function is the external effect of cultural capital in addition to the economic appeal of the place. This is partially known by Florida, Mellander (2010) as the effect of cultural amenities. Cultural amenities however refer to consumption (in any case of cultural amenity other than local cultural heritage objects). Living culture amenities such as theatres or concert halls for instance are indeed a proxy for local cultural capital and its attraction power for human capital. Econometric estimations, however, which use these amenities to capture the effect of cultural capital on economic development, are plagued with endogeneity and reverse causality. Therefore amenity-wise conceptualizations are also a weak theoretical approach for explaining the cultural capital effect of attracting human capital in a locality. We explicate this effect as the attraction mechanism of cultural capital. We measure it by approximating local cultural capital through the local values and beliefs which are historically shaped and path-dependent entities. In addition, we need to model the culturalvalue-dependent interaction between the attracted and incumbent human capital in the locality, which is crucial for the allocation of human capital to tasks and jobs. This distribution will either allow or hamper the effect of incoming creative human capital for the locality. The empirical operationalization of this understanding is applied in the following section for the case of the EU15 countries. 


\section{Empirical Evidence for Cultural Effects on the Benefits from Human Capital for Productivity}

\subsection{Database}

The empirical inquiry in this paper will refer to a compiled cross-section on culture, productivity and migration for the EU15 countries.

The compiled final dataset is on NUTS2 level, combining: 1) collapsed NUTS3 data from Eurostat Census 2001, 2) GDP per capita NUTS2 level data from the Regional Dataset of Eurostat, and 3) cultural indicators from the European and World Values Surveys (WVS) four-wave integrated data file, 1981-2004. The matched and cleaned final dataset contains 66 observations and drops the UK related data since the latter exists in an incompatible delimitation form.

The indicators in the above described datasets group in socio-economic indicators and cultural indicators.

The Eurostat information concerns the standard socio-economic indicators: number of people with tertiary education (informing our variable: share of human capital) and total unemployment rate. Eurostat is also the source for the data concerning the immigrants total number and the number of employed immigrants from EU, Europe, Russia, Asia and Africa. We transform all these variables into shares of total local population.

The local cultural capital will be measured as a composite cultural factor built up of 4 categories of different cultural indicators. The cultural indicators include positive and negative attitudes of locals obtained from the World Value Survey (WVS) database. These cultural indicators fall in four subcategories: 1) negative attitudes towards different race, Muslims, Jews, immigrants, homosexuals, 2) positive attitudes towards imagination, tolerance and obedience (as values people would like to teach their children), 3) attitudes towards work, if work needs to be creative and the motivation that drives people to work; 4) attitudes directly towards immigrants. The WVS collects its data with a structured questionnaire where we have identified the questions of interest and we have counted the number of people who have selected the answer of interest (See App. 1 for more details). Since the WVS provides representative data on NUTS2 level, the count of answers of interest divided by total population represents the share of people in a locality who have the particular attitude.

\subsection{Estimation Strategy}

In order to test our two hypotheses we will carry the following steps of estimation and analysis. 
First, we will conduct a factor analysis with the WVS data to identify main cultural factors in the local milieu. The identified cultural factor(s) will be included together with standard economic variables and different immigrant groups in a OLS regression with robust standard errors and productivity (measured as GDP per capita) as the dependent variable. The purpose of this estimation is to crosscheck the main assumption behind $\mathbf{H 0 1}$, namely: whether or not the effect of different immigrant groups on productivity is happening under a significant influence from the local cultural milieu. Second, to test the hypothesis H02, we will apply simultaneous equations method on our cross-sectional datasets. We will execute a double inquiry on: 1) the culture based preferences determining the immigrants' concentration (treating immigrants as a group of the human capital available in the locality) and 2) we will test the latter in the context of the cultural interaction between the different groups of human capital (skilled, creative and foreign/immigrants) attracted and formed in a locality. A simultaneous five equations model will be addressed for this purpose. Thanks to the rich database used in this study, we can infer cultural attitude variables that can be consider at large exogenous to migration and productivity and thus can serve as suitable instrumental variables in the model presented below. The Model represents an endogenous productivity model. The first three equations reflect the attraction gear of the cultural mechanism of impact (namely, the different groups of human capital are regressed on local productivity and employment as well as cultural instrumental variables).

The first equation models the share of immigrants as depending on local employment and overall economic conditions (presented by the GDP per capita), as well as the level of openness of the local cultural milieu with regards to special labour policy for immigrants, desires to assimilate those immirants and readiness to provide help to them, as well as the general milieu for which we plug in the instrumental variable: compassion.

$$
\begin{aligned}
& \text { Imm }_{-} T_{r}=\beta_{1} \text { Empl_T }_{r}+\beta_{2} \log G D P \_p c_{r}+\beta_{3} \text { Policy4Imm }_{r}+\beta_{4} \text { Assim }_{r}+\beta_{5} \text { Help2Imm }_{r}+ \\
& \beta_{6} \text { Compassion }_{r}+\varepsilon_{1 r}
\end{aligned}
$$

The second equation models the share of creative occupations in the local population as depending on local productivity and local employment opportunities, as well as on the level of tolerance and openness to the different (for which instrumental variable is the attitude to homosexuals as recommended by Richard Florida) and openness to new ideas as opposed to preference for obedience. These attitudes can readily be trusted to approximate successfully the cultural milieu with regards to its ability to welcome innovation and creativity. In addition, an instrument for the more general meaning of the cultural milieu for the creative occupations is summed by the variable of importance bestowed by the person to his partner moral.

$$
\begin{aligned}
& \text { Crea }_{r}=\beta_{7} \text { Empl_T }_{r}+\beta_{8} \log G D P \_p c_{r}+\beta_{9} \text { Toler }_{r}+\beta_{10} \text { Homo }_{r}+\beta_{11} \text { Idea }_{r}+\beta_{12} \text { Obedie }_{r}+ \\
& \beta_{13} \text { Partnermor }_{r}+\varepsilon_{2 r}
\end{aligned}
$$


The third equation explains the share of skilled workers in a locality with the total level of employment and economic development of the locality. In addition, the importance of the cultural factor is modelled by involving the instruments characterizing attitude to imagination and preference of innovation over struct following of instructions. Indeed, the latter sum up the presence of cultural barriers for creativity and productivity. Meanwhile, the share of skilled workers is also explained by the concentration of creative occupations and controlled for the share of immigrants, in line with background assumption of Florida's Creative Class concept, namely: that the creative workers are the ones who generate new ideas - and thus new jobs for the high-skilled to produce more through.

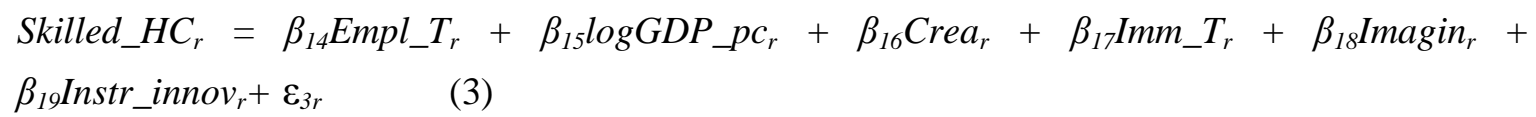

Equation (4) reflects the interaction gear of the cultural mechanism of impact, regressing total employment on the different human capital groups structuring the local labour market and the significance of culture in this context.

$E m p l \_T_{r}=\beta_{20} \operatorname{logGDP} \_p c_{r}+\beta_{21} I m m_{-} T_{r}+\beta_{22}$ Crea $_{r}+\beta_{23}$ Empl $_{-} T_{r}+\beta_{24}$ Partnermor $_{r}+\varepsilon_{4 r}$ (4)

Equation (5) reflects the importance of total employment and the concentration of the different groups of workers (skilled, creative and foreign) for local productivity. $\log G D P \_p c_{r}=\beta_{25} E m p l \_T_{r}+\beta_{26}$ Crea $_{r}+\beta_{27}$ Skilled_HC $C_{r}+\beta_{28} I m m \_T+\varepsilon_{5 r} r$ (5) where, $r$ signifies the locality and:

Imm_ $T_{r}-$ total share of immigrants;

$\mathrm{Crea}_{r}-$ share of workers with creative occupations;

Skilled_HC $C_{r}$ - share of highly skilled workers - human capital;

Empl_ $T_{r}$ - share of total employment;

$\log G D P \_p c_{r}-$ natural logarithm of local GDP per capita;

Policy4Imm $m_{r}$ - share of local people supportive for special labour policy for immigrants;

Assim $_{r}$ - share of local people supportive for assimilation for immigrants;

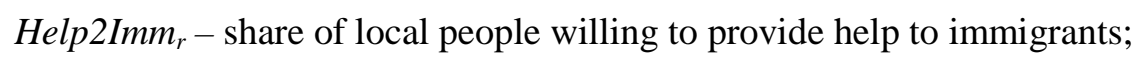

Compassion $_{r}$ - share of local people valuing compassion as an important moral asset;

Toler $_{r}$ - share of local people valuing tolerance as an important moral asset; 
$\mathrm{Homo}_{r}$ - share of local people with negative attitude to homosexuals;

$I d e a_{r}$ - share of local people skeptical towards new ideas;

Obedie $_{r}$ - share of local people valuing obedience as an important moral asset;

Partnermor $_{r}$ - share of local people valuing partner moral as essential for marriage;

$\operatorname{Imagin}_{r}$ - share of local people highly valuing imagination;

Instr_innov $v_{r}$ - share of local people valuing the struct following of instructions more than being innovative.

\subsection{Results}

The results from our factor analysis identified four cultural factors. Factor 1 is composed by negative attitudes to race, Muslims, immigrants and homosexuals, i.e. it represents the closed traditionalistic cultural milieu. Factor 2 unites positive attitudes towards imagination and initiative and tolerance, so that it summarizes the cultural openness in a locality. Factor 3 singles out the classical Weberian indicator of "calling” (i.e. our variable "work as duty to society"). Finally, factor 4 is composed by the indicators happiness, trust and national pride (strong group feeling) thus representing the local level of social capital (which we treat as a sub-category of cultural capital). Table 1 presents the results.

This factor analysis was performed alternatively on NUTS3 and NUTS2 levels of the WVS data, and the results remain essentially the same. Indifferent to the level of analysis and number of observations, the same indicators fall in the same four categories of main cultural factors.

As a first exploratory step we would like to check the relationship of these four cultural factors together with: local GDP per capita, the different types of local human capital (highly skilled and creative workers), total number of immigrants and the different subgroup of immigrants according to country of origin. Table 2 presents the results.

We observe strong negative relationship between culturally closed local milieu (factor 1) and total employment, and especially high negative correlation between this closedness and the concentration the creative workers. Meanwhile, open cultural milieu has an almost equally strong positive correlation with the concentration of both skilled (0.43) and creative workers (0.45 correlation coefficient). This gives a reason to expect that cultural traditionalism and closedness is likely to decrease the concentration of creative workers, and to expect that openminded cultural milieu attracts equally and perhaps stimulates equally the local productivity of all workers. Factors 3 and 4 have lower correlation with human capital and this is a reason to expect them to have lower significance for the attraction and productivity of human capital in a locality. Interesting to remark is also the relationship between creative workers and skilled workers, which amounts to a correlation of 0.2 , only, while both creative and skilled 
are highly correlated with productivity ( 0.60 and 0.59 , respectively). Yet, creatives are much more related with total employment generated in a locality (0.50), while the relationship between skilled and total employment is somewhat lower (0.4). This gives us intuition to expect Richard Florida's claim for the higher significance of creatives as generators of ideas and local employment (Florida 2005, 2002a,b; Florida, Mellander 2010) to be highly likely for the context of EU15 as well.

\section{Table 1: Principle Component Factor Analysis of WVS data - Loadings after Rotation}

\begin{tabular}{|l|rrrr|r|}
\hline \multicolumn{1}{|c|}{ Variable } & \multicolumn{1}{|c|}{ Factor1 } & \multicolumn{1}{c|}{ Factor2 } & \multicolumn{1}{c|}{ Factor3 } & Factor4 & Uniqueness \\
\hline happiness & $-0,0639$ & $-0,0212$ & $-0,1143$ & 0,7030 & 0,4882 \\
imagination & $-0,0192$ & 0,6050 & 0,0011 & $-0,1138$ & 0,6207 \\
tolerance & $-0,0335$ & 0,2768 & 0,2058 & 0,3176 & 0,7791 \\
obedience1 & 0,1080 & $-0,5674$ & 0,0091 & $-0,0296$ & 0,6654 \\
nb_race & 0,7717 & $-0,0143$ & $-0,0093$ & $-0,0533$ & 0,4013 \\
nb_musl & 0,7857 & 0,0018 & 0,0357 & 0,0498 & 0,3789 \\
nb_immigr & 0,7792 & $-0,0006$ & $-0,0467$ & $-0,0708$ & 0,3857 \\
nb_homo & 0,5733 & $-0,1635$ & 0,0104 & 0,0134 & 0,6443 \\
trust & $-0,1246$ & 0,3112 & 0,0041 & 0,4685 & 0,6681 \\
initiative & 0,1016 & 0,5133 & 0,1051 & 0,2260 & 0,6640 \\
w2duty & 0,0358 & $-0,0726$ & 0,8074 & 0,0435 & 0,3397 \\
instr_innov & $-0,0120$ & 0,2343 & $-0,1095$ & 0,1573 & 0,9082 \\
tradit_immig & $-0,0536$ & 0,0851 & 0,7854 & $-0,0901$ & 0,3649 \\
nationalism & 0,0914 & $-0,4450$ & 0,1242 & 0,4830 & 0,5449 \\
\hline
\end{tabular}

The table presents the factor loading after rotation, performed as final stage of principle component factor analysis. Four main cultural factors were identified through this analysis: factor 1 represents the cultural traditionalism and closedness, factor 2 represents the cultural openness and tolerance, factor 3 outlines the Weberian factor - the "calling" which treats work as a duty to society, and factor 4 sums up the social capital attitudes of trust and pride of group belonging (nationalism). The results presented are based on the WVS on NUTS2 level, after collapse. Identical four factors, with same distribution of the cultural variables within a factor were identified with the NUTS3 level of the data where the number of observations was significantly higher, the data being on individual level.

Source :Author's

To cross-check this intuition, several scatter plots are provided. Figures 1-6 present the relationship between creative, skilled workers and the four cultural factors as eventual determinants of local productivity.

The graphs confirm that we should expect a strong relationship between the effect of creative workers and local cultural openness (factor 2), both having the same angle of the fitted value line with local GDP per capita. Social capita cultural milieu - factor 4 - is equally associated with local productivity as much as the concentration of skilled workers. Factor 1 (closedness) and factor 3 (the Protestant attitude of work as a calling) seem negatively associated and in general less related to local productivity. 
Table 2: Correlations between Cultural Factors and Economic Variables

\begin{tabular}{|c|c|c|c|c|c|c|c|c|c|c|c|c|c|c|c|c|}
\hline \multirow{2}{*}{\begin{tabular}{|l|} 
facl \\
\end{tabular}} & \multirow{2}{*}{ 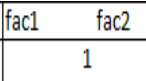 } & fac3 & fact & \multicolumn{3}{|c|}{ loggpd ${ }^{N} \mathrm{st} t^{N} \mid \mathrm{empl}$} & stotnus she & \multicolumn{2}{|c|}{ screa } & \multicolumn{2}{|c|}{ simm_t ${ }^{N} \mid$ stotal ${ }^{N} s$} & \multicolumn{3}{|c|}{ simm_t ${ }^{N} \mid$ simm_eu simm_ru } & \multicolumn{2}{|c|}{ simm_e $e^{N}$ simm_ ${ }^{N}$ ia simm_ ${ }^{N} \mathrm{ca}$} \\
\hline & & & & & & & & & & & & & & & & \\
\hline fac2 & $-0,19$ & 1 & & & & & & & & & & & & & & \\
\hline fac3 & $-0,02$ & $-0,37$ & 1 & & & & & & & & & & & & & \\
\hline fact & $-0,08$ & 0,54 & $-0,25$ & 1 & & & & & & & & & & & & \\
\hline loggpd_pc & $-0,20$ & 0,71 & $-0,31$ & 0,46 & 1 & & & & & & & & & & & \\
\hline stotalempl & $-0,34$ & 0,29 & $-0,34$ & 0,22 & 0,53 & 1 & 1 & & & & & & & & & \\
\hline stotnumres ${ }^{N}$ & $-0,52$ & 0,50 & $-0,32$ & 0,43 & 0,38 & 0,39 & 1 & & & & & & & & & \\
\hline shc & $-0,25$ & 0,43 & $-0,04$ & 0,39 & 0,59 & 0,41 & 0,25 & 1 & & & & & & & & \\
\hline screa & $-0,45$ & 0,45 & $-0,18$ & 0,15 & 0,60 & 0,50 & 0,61 & 0,20 & 1 & & & & & & & \\
\hline simm_total & $-0,33$ & 0,34 & $-0,34$ & 0,04 & 0,56 & 0,59 & 0,11 & 0,37 & 0,47 & 1 & & & & & & \\
\hline stotalnatios & 0,24 & $-0,25$ & 0,33 & 0,00 & $-0,45$ & $-0,40$ & 0,01 & $-0,29$ & $-0,36$ & $-0,87$ & 1 & & & & & \\
\hline simm_total & $-0,33$ & 0,34 & $-0,34$ & 0,04 & 0,56 & 0,59 & 0,11 & 0,37 & 0,47 & 1,00 & $-0,87$ & 1 & & & & \\
\hline simm_eu & $-0,30$ & 0,13 & $-0,33$ & 0,02 & 0,31 & 0,38 & 0,02 & 0,17 & 0,25 & 0,71 & $-0,61$ & 0,71 & 1 & & & \\
\hline simm_ru & 0,09 & $-0,06$ & 0,09 & 0,07 & $-0,06$ & 0,16 & $-0,13$ & 0,25 & $-0,30$ & 0,07 & $-0,03$ & 0,07 & 0,14 & 1 & & \\
\hline simm_europa & $-0,29$ & 0,31 & $-0,31$ & 0,04 & 0,54 & 0,55 & 0,12 & 0,36 & 0,44 & 0,96 & $-0,85$ & 0,96 & 0,65 & 0,04 & 1 & \\
\hline simm_asia & $-0,11$ & 0,44 & $-0,15$ & 0,13 & 0,68 & 0,36 & 0,06 & 0,39 & 0,43 & 0,66 & $-0,58$ & 0,66 & 0,36 & 0,00 & 0,58 & 1 \\
\hline simm_africa & $-0,08$ & 0,04 & 0,04 & $-0,06$ & 0,22 & 0,18 & $-0,14$ & 0,27 & 0,19 & 0,38 & $-0,30$ & 0,38 & 0,35 & 0,10 & 0,16 & 0,42 \\
\hline
\end{tabular}

The table presents levels of correlation between the cultural factors of cultural closedness, openness, Weberian calling and social capital proneness and the standard socio-economic variables: log GDP per capita, and shares of: total employment, total number of residents, highly skilled, creative, total number of immigrants, nationals, and immigrants from EU, Russia, Europe, Asia and Africa. Cultural factor openness seem highly correlated with creative (0.43) and skilled (0.45) workers and productivity (0.71), while the two categories of workers are only 0.20 correlated between each other.

Source :Author's

As far as the immigrants are concerned, our data indicates that the cultural factors seem overall important for their concentration. Yet, while immigrants from Europe and EU are concentrated according to the cultural milieu, the rest of the immigrants - from Russia, Asia and Africa have much lower relationship with the positive cultural factors. This gives a hint to expect that indeed, some groups of immigrants can exercise cultural preferences for their concentration, while others do not have a chance to do so. This can be also the explanation for the sharp differences between local productivity and the different immigrant groups - varying between highly significant coefficients for immigrants from Asia, whereas an even negative correlation is found for those coming from Russia. One should, however, be careful in the interpretation of these partial correlations since they do not capture the complex interrelationships. What we can conclude is that indeed $\mathbf{H 0 1}$ is supported by our data and we indeed find different impact from different groups of immigrants.

As a next step of our exploration, we conduct OLS estimations for the impact on GDP per capita generated by the different immigrant groups available from the Eurostat 2001 Census. Simultaneously, we control for the meaning of the local cultural milieu (represented by factors 1,2,3 and 4) as a context for the immigrants' effect on productivity. The results from our exploration are summarized in Table 3 below. 
Table 3: Immigrants' Impact, coefficients and t-values

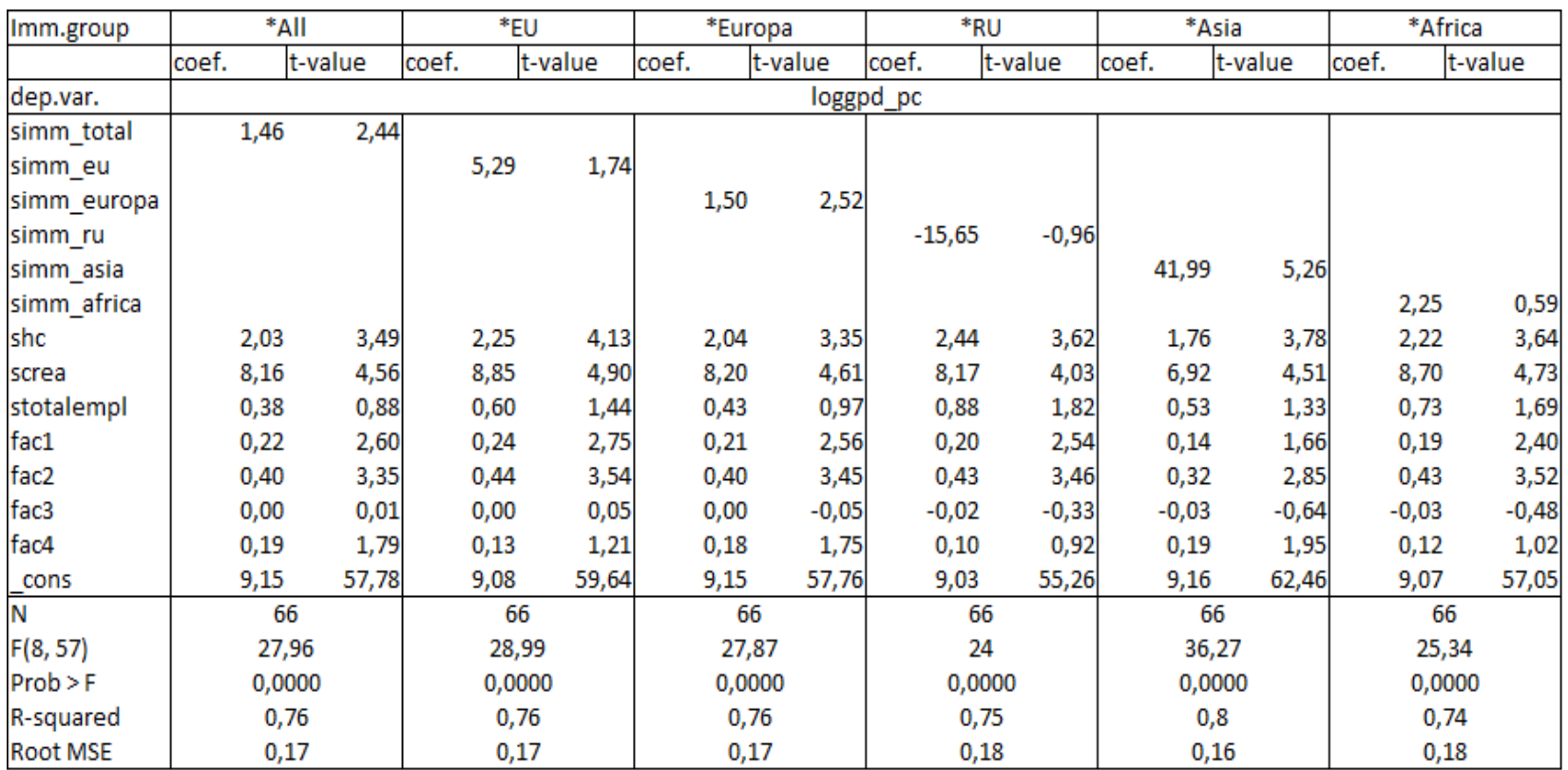

The table presents robust OLS estimations for local productivity, explained by local shares of creative and skilled human capital, total employment, cultural factors of closedness, openness, calling and social capital, and immigrants. The impact of different groups of immigrants according to their place of origin is tested in the different specifications. Immigrants in total seem to have positive effect for development, but this result investigated by different groups shows positive relationship between the concentration of Europeans, EU and Asian workers, while Russian and African workers are negative and insignificant factor for local productivity.

Source :Author's

As Table 3 shows, culture plays a highly significant role for local productivity, especially the level of openness or closedness of the milieu and social capital. Moreover, cultural factors outperform total employment as an explanatory factor for local productivity, while shares of creative and skilled workers survive as still highly significant variables.

Our result on the impact of immigrants as a whole is significant but relatively small as economic meaning, when immigrants are considered as a homogenous group. However, the regression analysis finds this immigrant impact to vary strongly among the different immigrant groups. While EU, European and Asian immigrants have respectively significant and highly significant influence on local productivity, Russian and African immigrants have negative, non-significant coefficients and t-values. These results partially corroborate with the findings of Ozgen et. al. 2010. And still, what we have registered by this finding is that indeed the impact of immigrants is different depending on the country of origin for the immigrants. Yet, the explanation for this phenomenon is not clear. On one side, the reason for this might be the fact that immigrants from some countries are much less skilled than immigrants from others. This however, is too courageous assumption, which neglects two important conditions. First, it is not only the skill level but the creativity which counts for productivity. Seminal works on entrepreneurship have given better insight on what drives the 
models of creativity - namely what we identified as creative human capital which is different from skilled human capital (Sahin et. al. 2011). On the other side, immigration is a process of self-selection, and those with highest tendency to risk taking and initiative are the ones who take the step to pay the cultural cost of migration (see Harris-Todaro (1970)). Thus, we have a self-selected highly initiative (associated with highly creative) individuals, who even if not highly skilled, are unlikely to generate negative effect, even if having a lower level or quality of education. Then, a different explanation for the different effect of the different group of immigrants could be the cultural capital effect (Bourdieu 1986) i.e. the bias resulting from the cultural belonging and origin, which affects social positioning and economic success of the individuals.

Our results register a positive effect from European and Asian, while negative from Russian and African immigrant groups. This phenomenon cannot be explained by the generally known from the literature cultural-distance (e.g. Kogut, Singh (1988); Grinblat, Keloharju (2001); Guo (2004); Tihanyi et. al (2005); Lee et. al (2008); Lucey, Zhang (2010)) and "home bias” (Duru, Reeb 2002; Chan et.al. 2005) effects. According to these two effects we should expect that: 1) the higher the cultural distance between newcomers and incumbent population, the better they will augment together the pool of knowledge with their diverse rational approaches and this will impact productivity but 2) the higher the cultural distance, the lower the tendency of the incumbent to invest in employment of culturally distant workers will be. Our evidence is mixed with regards to the effect on productivity and only partially supportive for home bias since Asians (who based on cultural distance should fall in the same category with Russians and Africans) are equally positively associated with local culture as Europeans and even more than EU immigrants in particular. Our finding can be rather better explained with the cultural embededness, which would claim that some groups end up in localities where innovation is better promoted by the local cultural mechanisms (Polanyi 1968, Tubadji 2012).

In summary, what we have for certain is only that the concentration of different groups of immigrants is associated with different local productivity while culture plays a highly significant positive effect on productivity and immigrants per se are also positively associated with productivity. This leads to the logical conclusion that the problem for the negative relationship between concentration of some groups of immigrants and local productivity might as well be that these groups end up concentrated in less culturally favourable for productivity localities. Then the right question to ask is how the concentration of immigrants happens vis a vis the important local cultural factor, when controlled for the effect of share of skilled and creative workers. 


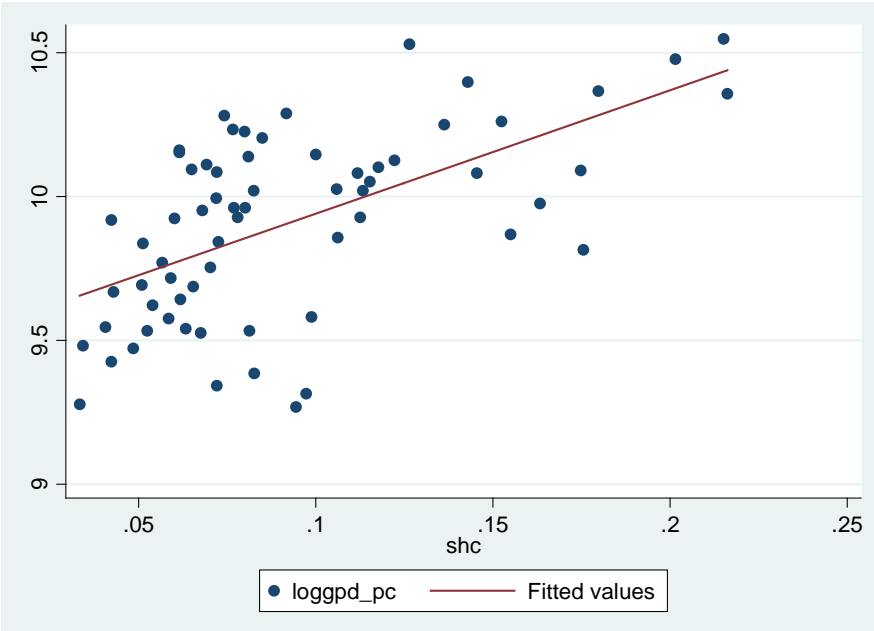

Figure 1: Relationship between skilled workers (share) and productivity (measured in gdp per cap).

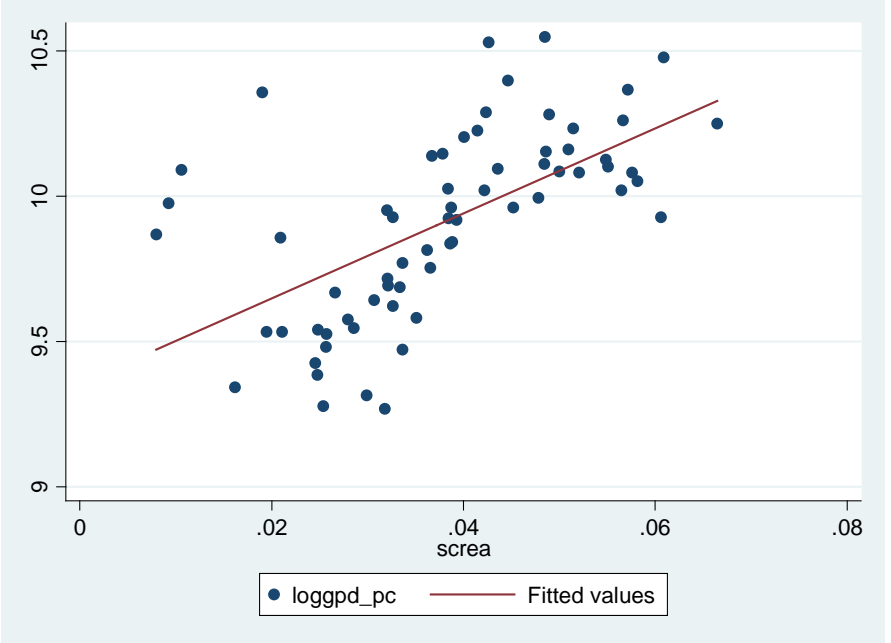

Figure 2: Relationship between creative workers (share) and productivity (measured in gdp per cap).

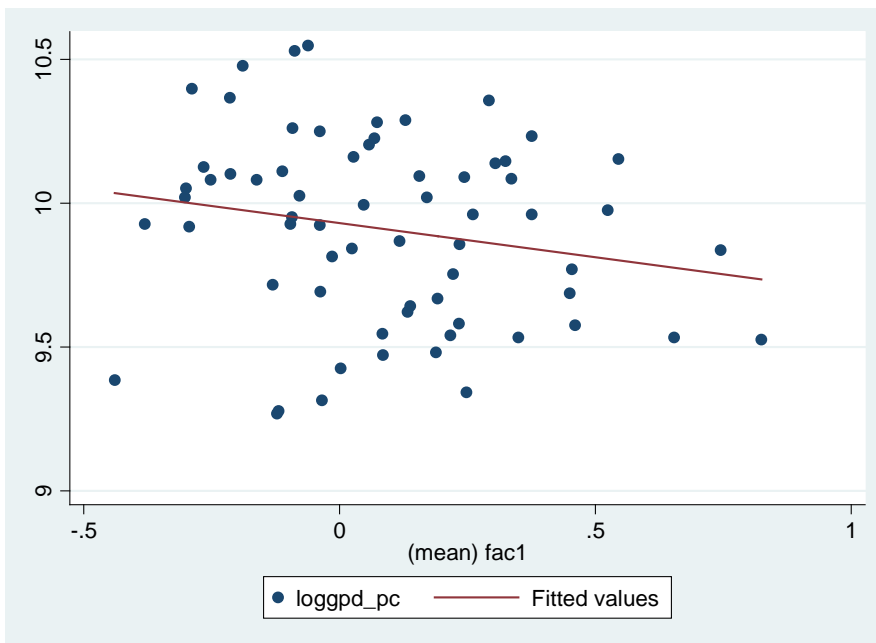

Figure 3: Relationship between cultural factor 1 (closed traditionalistic milieu) and productivity (measured in gdp per cap). 


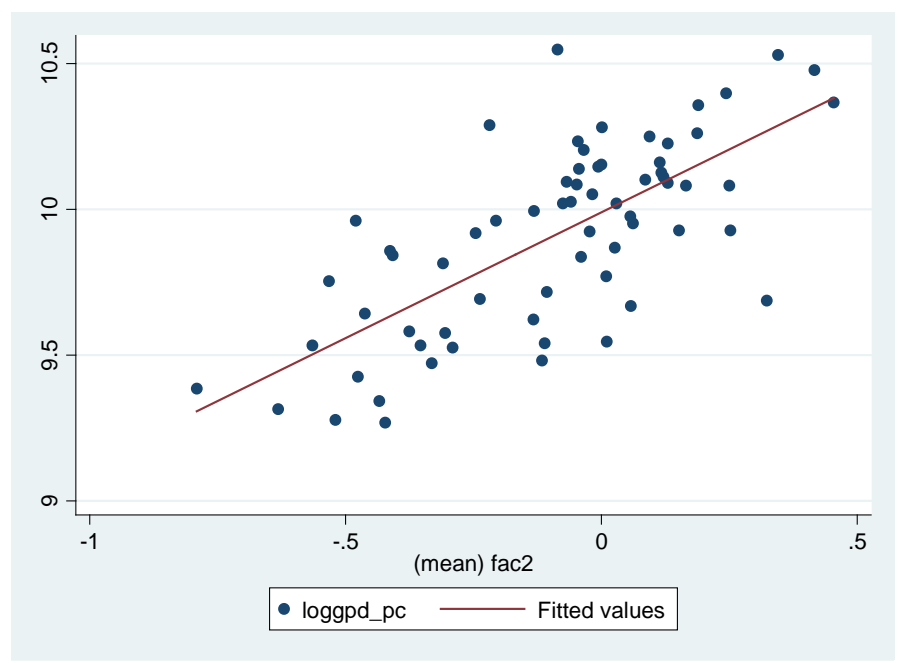

Figure 4: Relationship between cultural factor 2 (openness) and productivity (measured in gdp per cap).

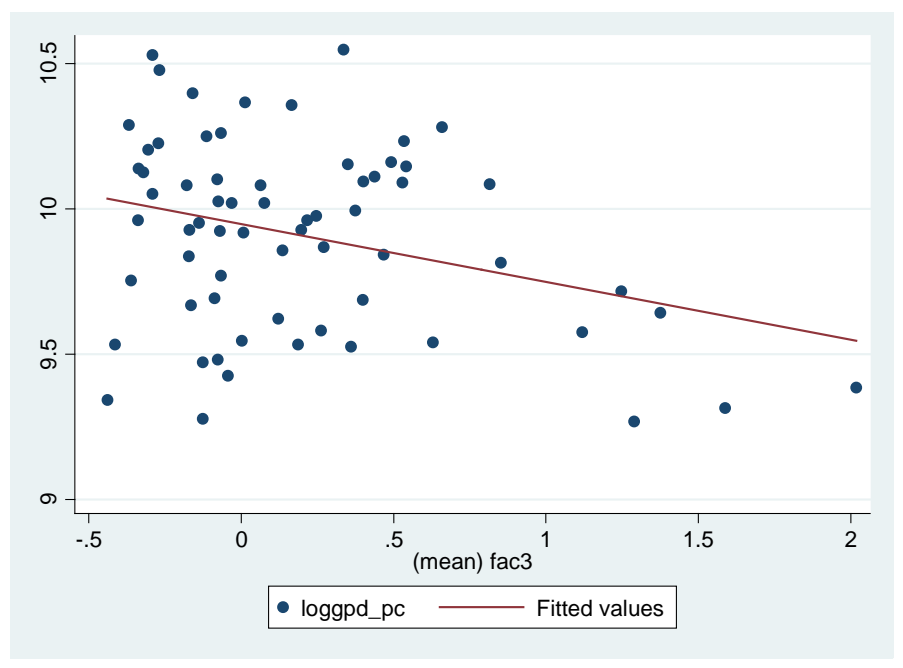

Figure 5: Relationship between cultural factor 3 (“calling”) and productivity (measured in gdp per cap).

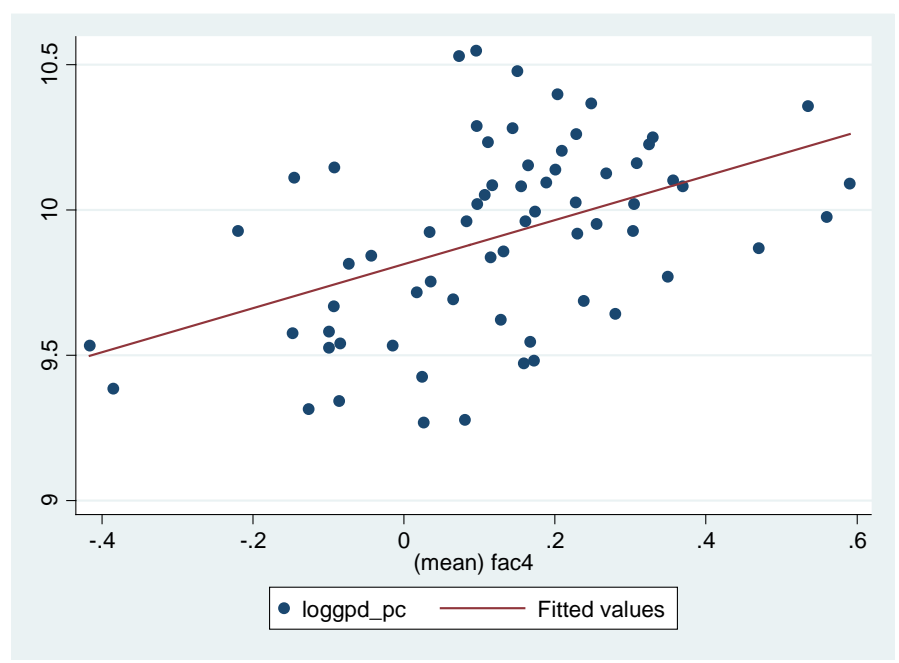

Figure 6: Relationship between cultural factor 4 (social capital) and productivity (measured in gdp per cap). 
To check precisely the latter thesis, we can examine the mechanism it assumes with a more comprehensive model, expressing cultural effect on the concentration of the different groups of human capital - immigrants, creative and skilled and their joint effect on labour and productivity in a locality. Th results of the five- equations model, described by eq. (1) to eq.(5) in the previous section, are presented in Table 4.

Table 4: Immigrant Preferences and Cultural Impact with Segmented Human Capital, coefficients and $t$-values

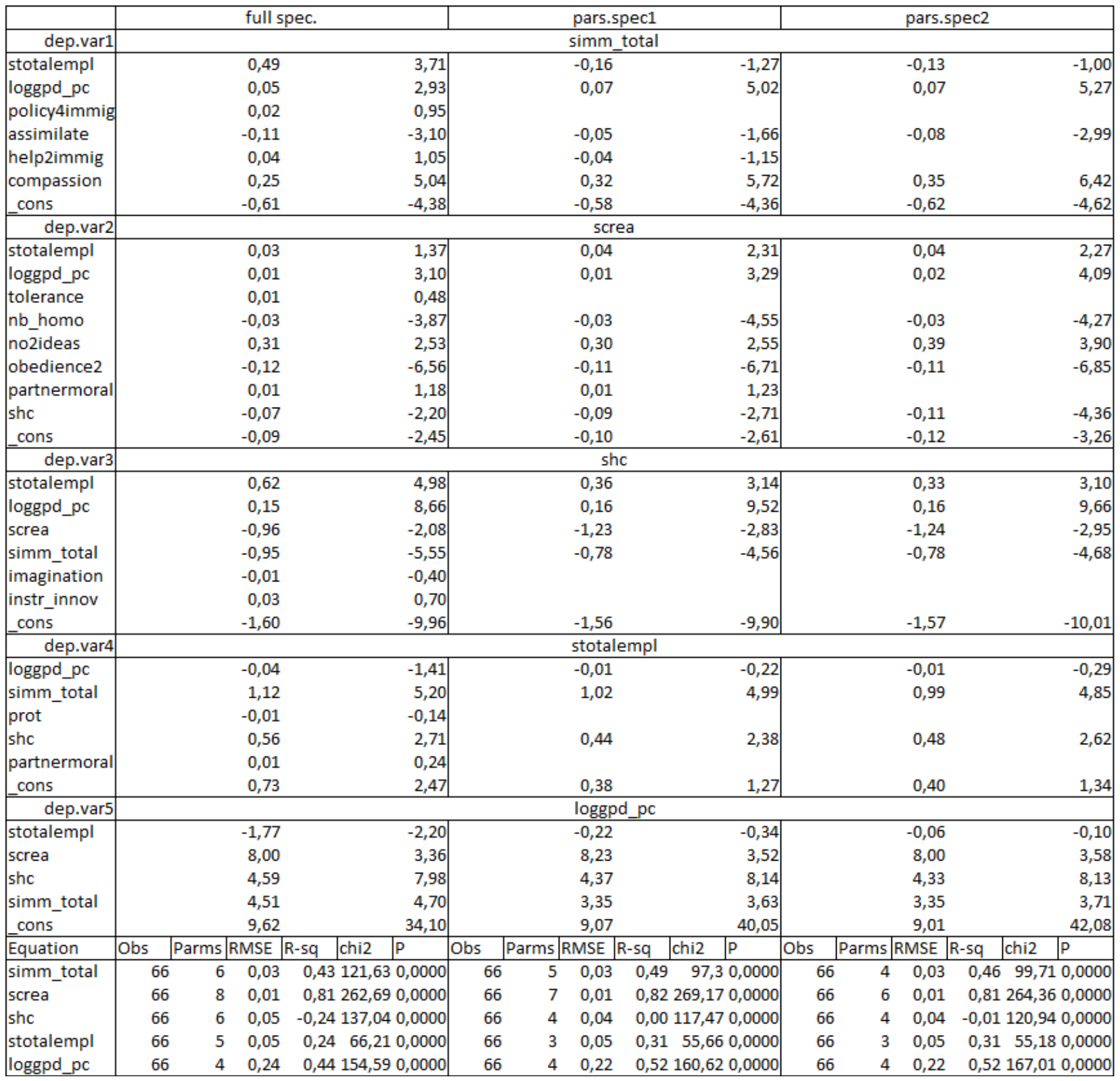

With our five simultaneous equations model, we look on: 1) the effect of local culture on the concentration of the different groups of human capital (skilled, creative and foreign workers) in a locality, and next 2) we question the potential of these different groups of human capital to act as determinants for local labour market size and as input for local productivity. In short, the meaning of the model is to examine the mechanism which explains the concentration of immigrants with local cultural milieu and then plugs them in the local human capital of skilled and creative workers in order to capture realistically their contribution for local productivity. The results demonstrate that concentration of workers depends on the local productivity and local cultural milieu, as well as the distribution of skilled and creative people, thus localities with positive cultural milieu and high level of productivity end up concentrating the more creative, skilled and productive immigrants. (Source: Authors') 
The analysis of our model regarding equation 1 identifies strong dependence of the concentration of immigrants on the productivity of a locality and its cultural milieu (positively associated with compassion and negatively associated with desire for assimilation). Equations 2 and 3 of our simultaneous model demonstrate dependence of the share of creative and skilled workers on local productivity and cultural milieu. These findings support Richard Florida's claim for the significance of the attitude towards homosexuals as an indicator for tolerance and the general attitude to ideas and innovation (which also supports the cultural link with Paul Romer's endogenous growth model - for details on this link please see Tubadji (2012)). Equation 4 of our model identifies local employment as dependent on the composition of the three groups of workers - creative, skilled and immigrants, but fails to detect such dependence from local productivity. Local productivity on its turn, according to our equation 5 of the model, is also strongly dependent on these three groups of human capital, but not on total employment. These results support an endogenous growth theory interpretation, where the important for productivity skilled and creative workers get distributed between localities according to the crucial for local development cultural factor. The latter supports the hypothesis that immigrant groups can have a negative effect only as long as these immigrants have ended up in a locality which has a cultural milieu which is less favourable for development. So, local cultural milieu is more important for local productivity of immigrants than the origin or creativity and skills of immigrants themselves. Based on the above, we can consider that the test of the five simultaneous equations model fails to reject our hypothesis H02. These findings can be considered a starting point for a serious investigations in this direction with richer datasets and more advanced methods.

\section{Conclusion}

Summing up the results from our inquiry, it seems that evidence from EU15 exists on regional level that indeed local cultural capital determines local productivity through a two levels mechanism. Namely, cultural capital is both a factor of attraction power for foreign human capital and a determinant for the efficient use of the accumulated different groups of human capital accumulated in the locality.

Thus, our results are compliant with the existent state of the art findings (Florida 2002a,b, 2005; Möller, Tubadji 2009) regarding the attraction power of cultural milieu, which influences the redistribution of human capital in the sense that people tend to migrate to places with more open cultural milieu. Moreover, we expand the state of the art with our understanding on both sides of the supply and demand influences of cultural capital. We find that besides being an amenity, living culture is a work environment criterion, which influences the migration choice and is exercised by those immigrants who have a higher bargaining power on the market. Furthermore, besides the effect on the migration choice of immigrants, local cultural capital influences the allocation of the incoming human capital to tasks (and jobs) 
locally. This is the main cultural interaction explanation why immigrants have different effect in different localities. Our results demonstrate that only when cultural capital lop-sides the natural distribution of creative people to creative jobs and trades creativity for high skills, the inflows of human capital might indeed end up with negative effects for some localities.

The limitations of this study however remain locked within a small dataset which allows for only primary degree of investigation. Therefore, we suggest our results as an innovative explanation for the discrepancies in the effect of immigration across EU15, arguing that the effect of immigrants can be approached by local policy in search for culturally more efficient socio-economic local context. For this purpose, further research agenda on the same model should involve inter- and intra-local differences in applying the model as well as the numerous scenarios for allocation of creative capital vis a vis the cultural capital and other bargaining powers of the incoming labourers.

\section{References}

Anderson, J. (2010), “The gravity model”, NBER Working Paper Series, Working Paper 16576, Cambridge, December 2010.

Autor, D. and Dorn, D. (2009), "Inequality and specialization: the growth of low-skill service jobs in the United States”, NBER Working Paper Series, Working Paper 15150, Cambridge, July 2009.

Becker, G. (1964, 1993, 3rd ed.), Human Capital: A Theoretical and Empirical Analysis, with Special Reference to Education, University of Chicago Press, Chicago.

Blinder, A. (2007), “How many U.S. jobs might be offshorable?”, CEPS Working Paper No. 142, Princeton University, March 2007.

Blinder, A. and Krueger, A. (2009), "Alternative measures of offshorability: a survey approach", NBER Working Paper Series, Working Paper 15287, Cambridge, August 2009.

Bourdieu, P. (1986), "The forms of capital”, in Richardson, J. (Ed.), Handbook of Theory and Research for the Sociology of Culture, Greenwood, New York, NY, pp. 241-258.

Bourdieu, P. (1973), "Cultural reproduction and social reproduction, knowledge, education and social change” , in Brown, R. (Ed.), Papers in the Sociology of Education, Tavistock Publications, Tavislock, UK, pp. 71-112.

Bourdieu, P. (1977), “Cultural reproduction and social reproduction”, in Karabel, J. and Halsey, A. H., (Eds.), Power and Ideology in Education, Oxford University Press, New York, NY, pp. 487-511.

Bourdieu, P. and J. Passeron (1977), Reproduction in Education, Society and Culture, (Richard Nice, Trans.), Sage, Beverly Hills, CA.

Bowles, S. and Gintis, H. (1975), "The problem with human capital theory - a Marxian critique”, American Economic Review, Vol. 65 No.2, pp. 74-82.

Chan, K., Covrig, V. and Ng, L. (2005), "What Determines the Domestic Bias and Foreign Bias? Evidence from Mutual Fund Equity Allocations Worldwide”, The Journal of Finance, Vol. 60 No. 3, pp. 1495-1534.

Duru, A. and Reeb, D. (2002), "International Diversification and Analysts' Forecast Accuracy and Bias”, The Accounting Review, Vol. 77 No. 2, pp. 415-433.

Florida, R. and Mellander, C. (2010), "There goes the metro: how and why Bohemians, artists and gays affect regional housing values”, Journal of Economic Geography, Vol. 10 No. 2, pp. 167188. 
Florida, R. (2005), The Flight of the Creative Class: The New Global Competition for Talent, Harper Collins, London, UK.

Florida, R. (2002a), The Rise of the Creative Class: And How it's Transforming Work, Leisure, Community, and Everyday Life, New York: Basic Books, New York, NY.

Florida, R. (2002b), “Bohemia and economic geography”, Journal of Economic Geography, Vol. 2, pp. 55-71.

Grinblat, M. and Keloharju, M. (2001) "How distance, language, and culture influence stockholdings and trades”, The Journal of Finance, Vol. 56 No. 3, pp. 1053 - 1073.

Guo, R. (2004), "How culture influences foreign trade: evidence from the US and China”, The Journal of Socio-Economics, Vol. 33, pp. 785-812.

Harris, J. and Todaro, M. (1970), "Migration, unemployment and development: a two-sector analysis", American Economic Review, Vol. 60 No. 1, pp. 126-42.

Jacobs, J. (1961), The Death and Life of Great American Cities, Vintage, New York.

Kogut, B. and Singh, H. (1988), "The effect of national culture on the choice of entry mode”, Journal of International Business Studies, Vol. 19, pp. 411-431.

Krueger, N. and Brazeal, D. (1994), "Entrepreneurial potential and potential entrepreneurs", Entrepreneurship Theory and Practice, Vol. 18 No. 2, pp. 91-104.

Krueger, N., Reilly, D. and Carsrud, A. (2000), "Competing models of entrepreneurial intentions", Journal of Business Venturing, Vol. 15 No. 5-6, pp. 411-432.

Lee, S., Shenkar, O. and Li, J. (2008), "Cultural distance, investment flow, and control in cross-border cooperation”, Strategic Management Journal, Vol. 29, pp. 1117-1125.

Lucey, B. and Zhang, Q. (2010), "Does cultural distance matter in international stock market comovement? Evidence from emerging economies around the world”, Emerging Markets Review, Vol. 11, pp. 62-78.

Marx, K. (1867), Capital, Vol. III, Ch. 29, International Publishers, New York, pp. 465-466.

Mincer, J. (1958), "Investment in human capital and personal income distribution”, The Journal of Political Economy, Vol. 66 No. 4, pp. 281-302.

Möller, J. and Tubadji, A. (2009), "The creative class, Bohemians and local labor market performance: a micro-data panel study for Germany 1975-2004” , Jahrbücher für Nationalökonomie und Statistik, Vol. 229 No. 2/3, pp. 270-291.

Nijkamp, P., Poot, J. and Sahin, M. (Eds.) (2011), "Migration Impact Analysis”. Edward Elgar, Cheltenham Northampton (forthcoming).

Ozgen, C., Nijkamp, P. and Poot, J. (2011), “Immigration and innovation in European regions”, IZA Discussion Papers 5676, Institute for the Study of Labor (IZA), Bonn, April 2011.

Ottaviano, G. and Peri, G.(2006), "The Economic Value of Cultural Diversity: Evidence from US Cities”, Journal of Economic Geography, Vol. 6, pp. 9-44.

Ottaviano, G. and Peri, G.(2005), “Cities and cultures”, Journal of Urban Economics, Vol. 58, pp. 304-337.

Ottaviano, G. and Peri, G. (2004), "The economic value of cultural diversity: evidence from US cities”, Cesifo Working Paper 1117, CESifo, Munich.

Ottaviano, G. and Prarolo, G. (2009), "Cultural identity and knowledge creation in cosmopolitan cities”, Journal of Regional Science, Vol. 49 No. 4, pp. 647-662.

Pigou, A. (1928), A Study in Public Finance, Macmillan, London, UK.

Polanyi, K. (1968), "The economy as an instituted process", in LeClair, E. E. and Schneider, H. K. (Eds.) Economic Anthropology: Readings in Theory and Analysis, Holt, Rinehart and Winston, Inc., New York, NY, pp. 122-43.

Rindermann, H. (2008), "Relevance of education and intelligence at the national level for the economic welfare of people”, Intelligence, Vol. 36, pp. 127-142.

Romer, P. (1986), "Increasing returns and long-run growth”, Journal of Political Economy, Vol. 94 No. 5, pp. 1002-1037. 
Romer, P. (1990), “Endogenous technological change”, Journal of Political Economy, Vol. 98 No. 5, pp. 71-102.

Romer, P. (1990), “Capital, labour and productivity”, Bookings Papers on Economic Activity: Microeconomics, 1990, pp. 337-367.

Sahin, M., Nijkamp, P. and Stough, R. (2011), "Impact of urban conditions on firm performance of migrant enterpreneurs: a comparative Dutch-US study”, Annals of Regional Science, Vol. 46, pp. 661-689.

Shapero, A. and Sokol, L. (1982), “The Social Dimensions of Entrepreneurship”, in Kent, C., Sexton, D. and Vesper, K.H. (Eds.) The Encyclopedia of Entrepreneurship, Prentice-Hall, Englewood Cliffs, NJ, pp. 72-90.

Smith, A. (1776), An Inquiry into the Nature and Causes of the Wealth of Nations, Book 2 - Of the Nature, Accumulation, and Employment of Stock, Black, Edinburgh.

Tihanyi, L., Griffith D. and Russell, J. (2005), "The effect of cultural distance on entry mode choice, international diversification, and MNE performance: a meta analysis”, Journal of International Business Studies, Vol. 36 No. 3, pp. 270-283.

Tubadji, A. (2011), "Culture Based Development hypothesis: a general theory of culture as a production factor”, forthcoming in International Journal of Manpower, Special Issue: Culture and Labour.

Tüzin B. and Nijkamp, P. (2011), “A socio-economic impact analysis of urban cultural diversity”, forthcoming in International Journal of Manpower, Special Issue: Culture and Labour. 


\section{Appendix 1: Cultural Indicators from the WVS}

This paper measures local cultural capital by using data on attitudes reported in the European and World Values Surveys (WVS) four-wave integrated data file, 1981-2004 (v.20060423). Our four categories of cultural indicators are informed by the WVS as follows: 1) negative attitudes towards different race, Muslims, Jews, immigrants, homosexuals (these are counts of people who indicated the particular group as someone they would mind having as a neighbour - answer to question A125, A128, A133, A129 and A132 from the WVS Questionnaire); 2) positive attitudes towards imagination, tolerance and obedience (as values people would like to teach their children - answer to question A034, A035, A042 and A044 from the WVS); 3) attitudes towards work, if work needs to be creative (the indicators 'initiative' and 'instr_innov' answering to positive response to question C016 (counting those who mentioned the need for using initiative as an important preference criteria for their job) and C061 (answers of interest are those stating 'it depends' if one has to always follow instructions or innovation is allowed from the WVS questionnaire) and the motivation that drives people to work (work as individual's duty - indicator we are interested in because of its link to Max Weber's notion of work as calling; related to question C039 from the WVS); 4) attitudes directly towards immigrants - negative, such as unwillingness to help immigrants (E166, answers 4 and 5) or disapproval of employment policy favouring the interests of immigrants at the labour market perceived as threat for the locals (question E143, answers 3 and 4) as well as positive attitudes such as concern for the wellbeing for the immigrants (E161, answers 1 and 2); in addition we have selected among others the attitudes towards the culture of immigrants (if they have to preserve their different cultural traditions (E145, answer 1) or they have to be assimilated (E145, answer 2) and 5) general attitudes of the people such as happiness (A008), depression (A017), remoteness from the other people (A013), trust (A165, answer 1) and nationalism (feelings of national pride question G006, answers 1 and 2). 